Nevşehir Bilim ve Teknoloji Dergisi Cilt 6(ICOCEE 2017 Özel Sayı) 326-332 2017

DOI: 10.17100/nevbiltek.322564

URL: http://dx.doi.org/10.17100/nevbiltek.322564

\title{
Fenton ve Fotofenton Prosesleri ile Atıksudaki Aspirinin Giderim Verimliliğinin Karşılaştırılması
}

\author{
Sevde ÜSTÜN ODABAŞI*, Bareera MARYAM, Hanife BÜYÜKGÜNGÖR \\ Ondokuz Mayıs Üniversitesi, Mühendislik Fakültesi, Çevre Mühendisliği Bölümü, Samsun
}

$\ddot{O} \mathbf{z}$

İlaçlar, sucul çevrede düşük konsantrasyonlarda bulunan önemli kirleticilerdir. Bu bileşikler, üretim sırasındaki atılımlarla, kullanılmayan veya kullanım süresi sona eren ilaçların atılmasıyla, insan ve hayvan boşaltımlarıyla birlikte çevreye farklı yollarla giriş yapmaktadırlar. Aspirin, steroid olmayan antienflamatuar (NSAID) bir ilaç olup, dünyanın hemen hemen her bölgesinde yaygın olarak kullanılmaktadır. Klasik atıksu arıtma tesisleri mikrokirleticilerin gideriminde yeterli olmamaktadır. Bu nedenle mikrokirletici giderimleri için ileri oksidasyon proseslerinin kullanılması iyi bir çözüm olmaktadır. Fenton ve fotofenton prosesleri ileri oksidayon proseslerinin alt basamağında bulunmaktadır. Bu çalışmada fenton ve fotofenton prosesleri kullanılarak aspirinin atıksudan giderimi amaçlanmıştır. Laboratuvar şartları altında, atıksuda bulunan aspirinin giderimi için $\mathrm{H}_{2} \mathrm{O}_{2}$ ve $\mathrm{FeSO}_{4}$ kullanılarak koagülasyon ve ileri oksidasyon yöntemleri uygulanmıştır. Aspirin tablet, musluk suyunda çözündürülerek konsantrasyonu $20 \mathrm{mg} / \mathrm{L}$ olacak şekilde hazırlanmıştır. Aspirinin giderim verimliliğini belirlemek için KOI ve TOK testleri yapılmıştır. Optimum $\mathrm{H}_{2} \mathrm{O}_{2}$ ve $\mathrm{FeSO}_{4}$ konsantrasyonlarını belirlemek için, farklı $\mathrm{pH}$ değerleri $(3,3.5,4)$, reaksiyon süresi $(10,20,30 \mathrm{dk})$ ve bekleme süresi (120 dk) seçilerek oda sıcaklığında deneyler gerçekleştirilmiştir. Fotofenton prosesinde ek olarak $254 \mathrm{~nm}$ dalgaboyu ışık tüm deneyler sırasında sürekli olarak uygulanmıştır. $\mathrm{H}_{2} \mathrm{O}_{2}$ ve $\mathrm{FeSO}_{4}$ konsantrasyonları $(10,20,30 \mathrm{mg} / \mathrm{L})$ denemiştir. Sonuçlar, fenton prosesi için $\% 83.91$ KOI ve $\% 57.52$ TOK giderimi ve fotofenton prosesi için \%90.97 ve \%85.89 TOK giderimi olduğunu göstermektedir.

Anahtar Kelimeler: Aspirin, Fenton prosesleri, İleri oksidasyon prosesleri, KOI, TOK.

\section{Comparison of Removal Efficiency of Aspirin in Wastewater by Fenton and Photo- Fenton Processes}

\begin{abstract}
Pharmaceuticals, as an emerging pollutant, are found in low concentration in aquatic environment. The residues of these compounds can enter the environment in different ways: during manufacturing and during the disposal of unused or expired drugs and with human and animal excretion. Aspirin (ASA), a non-steroidal anti-inflammatory drug (NSAID), is a most widely used medicine in almost every part of world. Classic wastewater treatment plants are not enough to remove micropollutants therefore advanced oxidation process have a good solution. Fenton and photo-fenton is a branch of advanced oxidation process. In this study, degradation of aspirin (ASA) using fenton and Photo-Fenton was studied in wastewater. Under laboratory conditions, coagulation and advance oxidation using $\mathrm{H}_{2} \mathrm{O}_{2}$ and $\mathrm{FeSO}_{4}$ was applied to degrade the concentrations of aspirin from wastewater. Aspirin tablet $(20 \mathrm{mg} / \mathrm{L})$ was dissolved in tap water to prepare aspirin solution as synthetic wastewater. COD and TOC test were conducted to observe the removal efficiency of drug. Experiments with optimal concentrations of $\mathrm{H}_{2} \mathrm{O}_{2}$ and $\mathrm{FeSO}_{4}$ were carried out by chancing $\mathrm{pH}(3-3.5-4)$, reaction time (10,20,30 $\mathrm{min})$ and residence time $(120 \mathrm{~min})$ of solution at room temperature and in the constant supply of UV $250 \mathrm{~nm}$ wavelength. Concentration of $\mathrm{H}_{2} \mathrm{O}_{2}$ and $\mathrm{FeSO}_{4}$ were selected as (10-20-30 mg/L). Results showed 83.91\% COD and $57.52 \%$ TOC removal for fenton process and $90.97 \%$ COD and $85.89 \%$ TOC removal for photo-fenton process.
\end{abstract}

Keywords: Aspirin, Fenton processes, Advanced oxidation process, COD, TOC.

*e-mail: sevde.ustun@omu.edu.tr 
1. Giriş

Gelişen teknoloji ve artan nüfus ile birlikte ilaçların kullanımı her geçen gün artmaktadır. Ancak bu ilaçlar kullanıldıktan sonra çevresel ortamdaki akıbetleri konusundaki bilgiler kısıtlıdır. Asetilsalisilik asit, modern adı ile aspirin, dünyada yaygın olarak kullanılan steroid olmayan antienflamatuar, aneljezik ve antipretik bir ilaçtır [1 ve 2]. Aspirin, hafif ağrıların ve ateşin gideriminde, kroner kalp hastalıklarında ve gebelikte oluşan preeklemsi hastalığının önlenmesinde kullanılmaktadır [2]. Aspirin vücuda alındıktan sonra, bir kısmı metabolizmada emilirken, bir kısmı ise idrar ve dışkı yoluyla atılmaktadır. Böylece kanalizasyon oradan da atıksu arıtma tesislerine ulaşır. Bu sırada biyolojik olarak bozunmazlar ya da atıksu arıtma tesislerinde giderilmezse yüzey sularına ulaşabilmektedir [3 ve 4]. Sularda tespit edilen ilaç kalıntıları diğer kirleticilere göre düşük oranda (ng/L- $\mu \mathrm{g} / \mathrm{L})$ bulunsada insan ve çevre sağlığı üzerinde meydana getirdiği etkiler oldukça önemlidir [5]. Bu etkilerden bazıları cinsiyet tersinimleri, cinsiyet oranlarının değişmesi ve canlı populasyonlarının azalmasıdır.

İlaç kalıntıları içeren suların klasik atıksu arıtma tesislerinde giderimi tam olarak gerçekleşmemektedir. Bu nedenle bu kalıntıların giderimi için ileri arıtım yöntemleri kullanılmaktadır [6 ve 7]. Bu yöntemlerin başında fenton prosesler, membran sistemler, ultraviolet, ozonlama ve bunların oluşturduğu hibrit prosesler gelmektedir [8 ve 9]. Bu proseslerden fenton oksidasyonu, hızlı olması, düşük maliyetli olması, basit teknolojili olması nedeniyle ilaçların gideriminde sıkça kullanılan cazip bir yöntemdir.

Fenton prosesi ile gerçekleştirilen arıtım, oksidasyon, nötralizasyon, koagülasyon/flokülasyon ve çökelme olmak üzere dört aşamadan oluşmaktadır [7]. Fenton reaksiyonu olarak bilinen reaksiyon, $\mathrm{Fe}^{+2}{ }^{+1}$ in $\mathrm{OH}^{*}$ meydana getirmek üzere $\mathrm{H}_{2} \mathrm{O}_{2}$ ile oksidasyonudur [10].

$$
\mathrm{Fe}^{+2}+\mathrm{H}_{2} \mathrm{O}_{2} \rightarrow \mathrm{OH}^{\cdot}+\mathrm{OH}^{-}+\mathrm{Fe}^{+3}
$$

Fenton prosesinin verimliği; $\mathrm{Fe}^{+2}$ ve $\mathrm{H}_{2} \mathrm{O}_{2}$ dozu, ortamın $\mathrm{pH}$ değeri, sicaklık ve atık organik maddelerin derişiminden etkilenmektedir. Fenton proseslerinde optimum pH değeri 2 ile 4 arasındadır. pH 2 değerinden küçük olursa kompleks demir bileşikleri oluşur ve reaksiyon yavaşlar. Yüksek pH değerlerinde ise 4 'ten büyük olduğu zaman ise ferrik-hidroksi bileşikleri oluşumu nedeniyle radikal oluşumu yavaşlamaktadır. Bu nedenle optimum $\mathrm{pH}$ değeri genellikle 3 civarında olduğu tesit edilmiştir. Diğer bir önemli parametre ise hidrojen perokist dozudur. Hidrojen peroksit dozu arttıkça parçalanma hızı artmaktadır. Ancak, ortamda fazla miktarda hidrojen peroksit bulunması hidroksil radikalleriyle reaksiyona girerek proses performansı düşmektedir. Ayrıca hidrojen peroksit sürdürülebilir bir madde olmadığı için çevre açısında çok fazla tüketilmemesi gerekmektedir [7].

Ayrıca fenton prosesinin etkinliği ultraviole ışınları ile birlikte geliştirilebilmektedir. UV ışığının varlığında gerçekleşen Fenton prosesi, foto-fenton prosesi olarak adlandırılmaktadır. Bu yöntemde $\mathrm{OH}^{*}$, $\mathrm{Fe}^{+2}$ fotolizi ve $\mathrm{Fe}^{+2}$ ile $\mathrm{H}_{2} \mathrm{O}_{2}$ reaksiyonuyla oluşmaktadır [10].

$$
\begin{aligned}
& \mathrm{Fe}^{+2}+\mathrm{H}_{2} \mathrm{O}_{2} \rightarrow \mathrm{FeOH}^{+2}+\mathrm{OH}^{\bullet} \\
& \mathrm{FeOH}^{+2}+\mathrm{h} v \rightarrow \mathrm{Fe}^{+2}+\mathrm{OH}^{\cdot}
\end{aligned}
$$


Fotofenton reaksiyonundaki parçalanma hızı klasik fenton reaksiyonuna göre çok daha büyüktür ve ayrıca oluşan çamur hacmi daha azdır. Fotofenton prosesindeki işletme maliyeti, kimyasal tüketimi klasik fenton prosesine göre çok daha düşüktür. Tüm bu nedenlerle fotofenton prosesi klasik fenton prosesine göre daha avantajlı bir yöntemdir[11].

$\mathrm{Bu}$ çalışmada, aspirin hedef kirletici olarak seçilmiştir. Aspirinin giderim verimi, fenton ve fotofenton prosesleri ile karşılaştırılmıştır. Karşılaştırma işlemi yapılırken her iki sistem için optimum oksidant dozu, $\mathrm{pH}$ ve karıştırma zamanı denenmiştir. Aspirinin giderimi KOI ve TOK testleri ile belirlenmiş ve optimum koşullardaki sistemin seçilmesi amaçlanmıştır.

\section{Materyal ve Metot}

\subsection{Kimyasallar}

Atıksu numunelerine fenton ve fotofenton deneyleri yapılarak KOI ve TOK giderim verimleri araştırılmıştır. Fenton deneylerinde kullanılan kimyasal maddeler hidrojen peroksit (\%35 w/w, Merck), $\mathrm{FeSO}_{4} .7 \mathrm{H}_{2} \mathrm{O}$ (\%99.5, Sigma Aldrich), Sulfürik asit (\%98, Merck), Sodyum hidroksit (>\%99, Merck) olup tüm deneyler oda sıcaklığında gerçekleştirilmiştir. KOI deneylerinde kullanılan kimyasallar, potasyum dikromat (>\%99, Merck), Demir amonyum sülfat (\%99, Carlo Erba), 1.10-Fenontrolin ve monohidrat (>\%99.9, Sigma Aldich), Aluminyum sülfat (>\%98, Sigma Aldrich), Gümüş sülfat (>\%98, Sigma Aldrich) olup tüm solusyonlar distile su ile hazırlanmıştır.

\subsection{Analitik Yöntemler}

Deneyde kullanılan atıksuyun pH değerleri bir pH metre (Ohasus-starter3100) ile ölçülmüştür. KOI (mg/L) ölçümleri standart metotlarda verilen yönteme göre yapılmıştır [12]. KOI analizleri için kullanılan termoreaktör Spectroquant-TR420 markası ile yapılmıştır. TOK analizleri ise Apollo 9000 combustion TOC analyzer cihazı ile gerçekleştirilmiştir.

\subsection{Deneysel Prosedürler}

Fenton oksidasyon deneylerinde kullanılan atıksu, aspirin tabletin toz haline getirilip musluk suyunda çözünmesi ile hazırlanan $20 \mathrm{mg} / \mathrm{L}$ derişiminde bir sentetik sudur. Fenton ve fotofenton prosesleri ile aspirinin indirgenmesi incelenirken giderim verimi KOI ve TOK ile ölçülmüştür. Bunları etkileyen parametrelerin optimum değerlerini belirlemek amacıyla dört aşamada gerçekleştirilmiştir.

İlk aşamada, optimum pH değerini belirlemek için 3, 3.5, 4 değerleri $300 \mathrm{ml}$ atıksu örneklerinde denemiştir. $1000 \mathrm{mg} / \mathrm{L}$ 'lik $\mathrm{Fe}^{+2}$ çözeltisi $\mathrm{FeSO}_{4} \cdot 7 \mathrm{H}_{2} \mathrm{O}$ 'den $\mathrm{H}_{2} \mathrm{O}_{2}$ ise $1.13 \mathrm{~g} / \mathrm{mL}$ yoğunluğunda $\% 35$ 'lik $\mathrm{H}_{2} \mathrm{O}_{2}$ 'den hazılanmıştır. Atıksu numunelerinin $\mathrm{pH}$ değerleri $1 \mathrm{~N}_{2} \mathrm{SO}_{4}$ ve $1 \mathrm{~N} \mathrm{NaOH}$ kullanılarak istenilen değerlere getirilmiştir. Daha sonra atıksuya denenecek parametrelerin orta değer olan $20 \mathrm{mg} / \mathrm{L}$ $\mathrm{FeSO}_{4} \cdot 7 \mathrm{H}_{2} \mathrm{O}$ eklenmiş̧tir. $\mathrm{FeSO}_{4} .7 \mathrm{H}_{2} \mathrm{O}$ 'nin çözünmesi için karıştırılmış daha sonra $\mathrm{H}_{2} \mathrm{O}_{2}$ eklenmiştir. Jar testinde 1 dakika 300 rpm ve 19 dakika 100 rpm seçilmiştir. Gerekli süre sonunda ortamdaki $\mathrm{Fe}(\mathrm{OH}) 3^{\prime}$ ün tepkimesi durdurmak için pH 7-8' e getirilmiştir. Daha sonra örnekler 120 dakika çökelme süresine bırakılmıştır. Çökelme süresi sonunda üst fazdan $150 \mathrm{ml}$ numune alınarak KOI ve TOK testleri yapılmıştır. Tüm aşamalar fotofenton prosesleri içinde gerçekleştirilmiştir. Deneyler gerçekleştirilirken $254 \mathrm{~nm}$ dalga boyunda ışıklar ultraviole lambası sürekli olarak uygulanmıştır. 
İkinci deney serisinde birinci aşamada elde edilen optimum $\mathrm{pH}$ değerine karşıllık farklı $\mathrm{Fe}^{+2}$ konsantrasyonları (10-20-30 mg/L) denenmiştir.

Üçüncü deney serisinde ise, optimum $\mathrm{pH}$ ve $\mathrm{Fe}^{+2}$ konsantrasyon değerlerine karşıllk farkl $\mathrm{H}_{2} \mathrm{O}_{2}$ konsantrasyonları (10-20-30 mg/L) denenmiştir.

Dördüncü deney serisinde ise, optimum $\mathrm{pH}, \mathrm{Fe}^{+2}$ ve $\mathrm{H}_{2} \mathrm{O}_{2}$ konsantrasyonlarında farklı reaksiyon süreleri $(10,20,30 \mathrm{dk})$ için aynı işlemler yapılarak optimum reaksiyon süresi belirlenmiştir. Bütün deney serilerindeki şartlar Tablo 1' de verilmiştir.

\begin{tabular}{|c|c|c|c|c|c|c|c|c|}
\hline & \multicolumn{2}{|c|}{ pH } & \multicolumn{2}{|c|}{$\mathrm{Fe}^{+2}(\mathrm{mg} / \mathrm{L})$} & \multicolumn{2}{|c|}{$\mathrm{H}_{2} \mathrm{O}_{2}(\mathrm{mg} / \mathrm{L})$} & \multicolumn{2}{|c|}{ Reaksiyon Süresi (dk) } \\
\hline & Fenton & Fotofenton & Fenton & Fotofenton & Fenton & Fotofenton & Fenton & Fotofenton \\
\hline \multirow[t]{2}{*}{ Seri 1} & Araştırılan & Araştırılan & 20 & 20 & 20 & 20 & 20 & 20 \\
\hline & Değer & Değer & & & & & & \\
\hline \multirow[t]{2}{*}{ Seri 2} & 3.5 & 3.5 & Araştırılan & Araştırılan & 20 & 20 & 20 & 20 \\
\hline & & & Değer & Değer & & & & \\
\hline Seri 3 & 3.5 & 3.5 & 10 & 20 & $\begin{array}{l}\text { Araştırılan } \\
\text { Değer }\end{array}$ & $\begin{array}{c}\text { Araştırılan } \\
\text { Değer }\end{array}$ & 20 & 20 \\
\hline Seri 4 & 3.5 & 3.5 & 10 & 20 & 20 & 10 & $\begin{array}{l}\text { Araştırılan } \\
\text { Değer }\end{array}$ & $\begin{array}{c}\text { Araştırılan } \\
\text { Değer }\end{array}$ \\
\hline Optimum & 3.5 & 3.5 & 10 & 20 & 20 & 10 & 30 & 30 \\
\hline Değer & & & & & & & & \\
\hline
\end{tabular}

\section{Bulgular}

Bu çalışmada kullanılan atıksuyun başlangıçtaki özellikleri Tablo 2'de verilmiştir.

\begin{tabular}{ccc} 
Tablo 2. Çalışmada kullanılan atıksuyun özellikleri \\
\hline Parametre & Birim & Değer \\
pH & - & 7.01 \\
TDS & $\mu \mathrm{S} / \mathrm{cm}$ & 401 \\
Bulanıklık & $\mathrm{NTU}$ & 1.30 \\
Sicaklık & ${ }^{\circ} \mathrm{C}$ & 23.00 \\
Çözünmüş Oksijen & $\mathrm{mg} / \mathrm{L}$ & 6.98 \\
KOI & $\mathrm{mg} / \mathrm{L}$ & 608 \\
TOK & $\mathrm{mg} / \mathrm{L}$ & 95.19
\end{tabular}

\section{1. $\quad$ pH Etkisi}

Yapılan çalışmalar incelendiğinde fenton oksidasyon prosesinin en iyi oluşuğu $\mathrm{pH}$ aralığı 2-4 olarak belirlendiği tespit edilmiştir [13 ve 14]. Bu çalışmada da aspirin için optimum pH değerinin belirlenmesi için 3, 3.5 ve 4 değerleri denenmiştir. Deneyler gerçekleştirilirken atıksuya eklenen $\mathrm{Fe}^{+2}$ dozu ve $\mathrm{H}_{2} \mathrm{O}_{2}$ dozu $20 \mathrm{mg} / \mathrm{L}$, reaksiyon süresi 20 dakika olarak seçilmiştir. Çalışmada hem fenton prosesi hem de fotofenton prosesi için optimum pH değeri 3.5 olarak bulunmuştur. Ustun Odabaşı v.d' nin (2016, 2017) Fenton oksidasyonu ile parasetamol ve ibuprofen içeren atıksuyun arıtımında optimum $\mathrm{pH}$ değerini yaklaşık 3.5 olarak tespit etmişlerdir [15 ve 16]. Sonmez (2015) fenton oksidasyonu ile karbamazepin ve 
kafein içeren atıksuyun arıtımında optimum pH değeri 3.5 civarında bulmuştur [7]. Analiz sonuçları Şekil 1(a)' da verilmiştir.

\section{2. $\mathrm{Fe}^{+2}$ Dozunun Etkisi}

$\mathrm{Fe}^{+2}$ konsantrasyonunun atıksudan aspirin giderim verimine olan etkisini belirlemek amacıyla $\mathrm{pH}$ 3.5 değerinde 10, 20, $30 \mathrm{mg} / \mathrm{L}$ arasında değişen konsantrasyonlar denenmiştir. Deneyler gerçekleştirilirken atıksuya eklenen $\mathrm{H}_{2} \mathrm{O}_{2}$ dozu $20 \mathrm{mg} / \mathrm{L}$, reaksiyon süresi ise 20 dakika olarak seçilmiştir. Yapılan KOI ve TOK analizleri sonucunda fenton prosesi için $\mathrm{Fe}^{+2}$ konsantrasyonu $10 \mathrm{mg} / \mathrm{L}$ ve fotofenton prosesi için $\mathrm{Fe}^{+2}$ konsantrasyonu ise $20 \mathrm{mg} / \mathrm{L}$ olarak bulunmuştur. $\mathrm{Bu}$ analizlerle ilgili sonuçlar Şekil 1(b)' de verilmektedir.

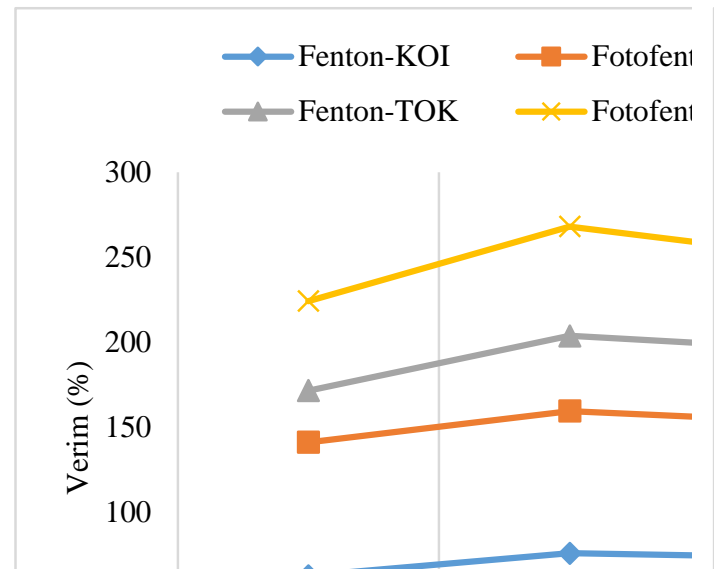

(a)

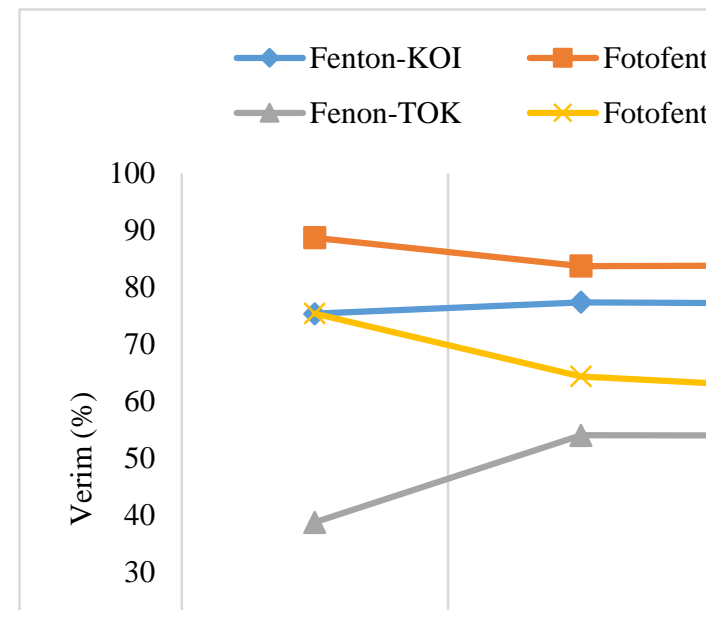

(c)

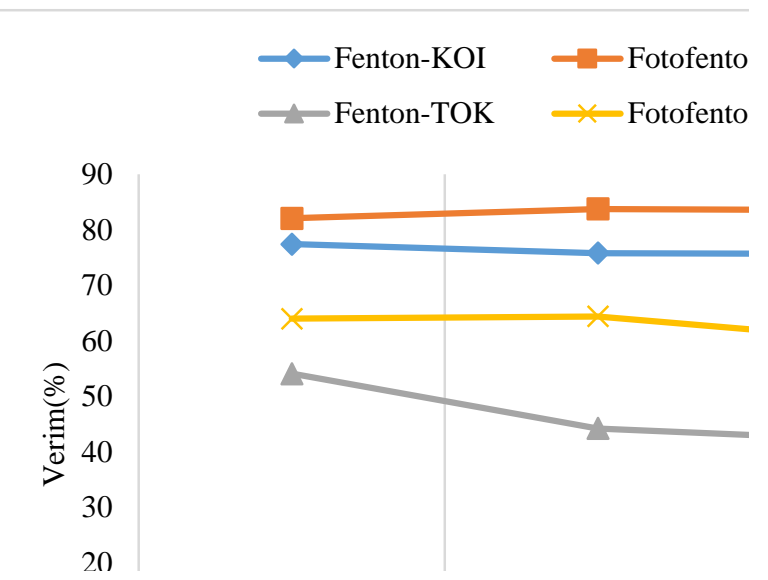

(b)

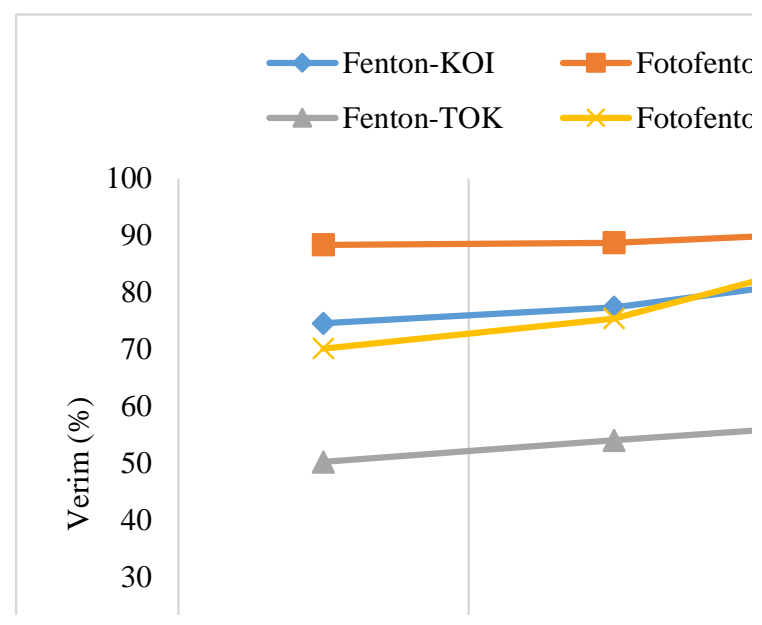

(d)

Şekil 1. Fenton ve fotofenton prosesinin KOI ve TOK giderim verimlerinin karşılaştırılması a) $\mathrm{pH}$, b) $\mathrm{Fe}^{+2}$ dozu, c) $\mathrm{H}_{2} \mathrm{O}_{2}$ dozu, d)Reaksiyon süresi

\section{3. $\quad \mathrm{H}_{2} \mathrm{O}_{2}$ Dozunun Etkisi}

$\mathrm{H}_{2} \mathrm{O}_{2}$ konsantrasyonunun atıksudan aspirin giderim verimine olan etkisini belirlemek amaciyla pH 3.5 değerinde 10, 20, $30 \mathrm{mg} / \mathrm{L}$ arasında değişen konsantrasyonlar denenmiştir. Deneyler gerçekleşirken eklenen $\mathrm{Fe}^{+2}$ dozu fenton prosesi için $10 \mathrm{mg} / \mathrm{L}$ ve fotofenton prosesi için ise $20 \mathrm{mg} / \mathrm{L}$, reaksiyon süresi ise her iki proses için 20 dakika olarak seçilmiştir. Yapılan KOI ve TOK analizleri 
sonucunda fenton prosesi için $\mathrm{H}_{2} \mathrm{O}_{2}$ konsantrasyonu $20 \mathrm{mg} / \mathrm{L}$ ve fotofenton prosesi için $\mathrm{H}_{2} \mathrm{O}_{2}$ konsantrasyonu $10 \mathrm{mg} / \mathrm{L}$ olarak bulunmuştur. Bu analizler ile ilgili sonuçlar Şekil 1(c)' de verilmiştir. Literatür çalışmaları göstermektedir $\mathrm{ki}_{2} \mathrm{O}_{2}$ dozu arttıkça oksidasyon verimi artmaktadır. Ancak $\mathrm{H}_{2} \mathrm{O}_{2}$ ' in sürdürülebilir bir kimyasal olmayışı ve fazla miktarda $\mathrm{H}_{2} \mathrm{O}_{2}$ bulunması hidroksil radikalleri ile reaksiyona girmesine sebep olduğu için fazla kullanımı tercih edilmemektedir [7 ve 17]. Fotofenton prosesinde daha az $\mathrm{H}_{2} \mathrm{O}_{2}$ kullanımıyla etkin bir giderim verimi elde edilmiştir. $\mathrm{Bu}$ sonucun ultraviole ışınlarının etkinlğinden kaynaklanmakta olduğu düşünülmektedir. Analizler ile ilgili sonuçlar Şekil 1(c)’ de verilmiştir.

\subsection{Reaksiyon Süresinin Etkisi}

En son adıma kadar her iki proses içinde 20 dakika karıştırma işlemi yapılmıştır. Reaksiyon süresinin fenton ve fotofenton prosesleri üzerine etkisini incelemek üzere 10, 20, 30 dakika süreler içerisinde hızlı ve yavaş karıştırma yapılmıştır. Sonuçlar incelendiğinde ise her iki proses içinde optimum reaksiyon süresinin 30 dakika olduğu tespit edilmiştir. Reaksiyon süresi arttıkça fenton ve fotofenton proseslerinin verimliliği de artmıştır. Bu kapsamda analizler 45 dakika içinde tekrarlanmıştır ancak verimlilik 30 dakikadan daha düşük çıkmıştır. Bu sonuçlara bakıldığında, her iki proses için 30 dakikanın optimum reaksiyon süresi olduğu bulunmuştur. Şekil 1(d)' de analizler ile ilgili sonuçlar verilmiş̧tir.

\section{Tartışma ve Sonuç}

Fenton ve fotofenton prosesi ile aspirin gideriminin karşılaştırılması yapıldığında sonuçlar fenton prosesi için; $\mathrm{pH} 3.5, \mathrm{Fe}^{+2} 10 \mathrm{mg} / \mathrm{L}, \mathrm{H}_{2} \mathrm{O}_{2} 20 \mathrm{mg} / \mathrm{L}$, reaksiyon süresi 30 dakika ve fotofenton prosesi için ise $\mathrm{pH} 3.5, \mathrm{Fe}^{+2} 20 \mathrm{mg} / \mathrm{L}, \mathrm{H}_{2} \mathrm{O}_{2} 10 \mathrm{mg} / \mathrm{L}$, reaksiyon süresi 30 dakika olarak bulunmuştur. Bu değerlere göre oda sıcaklığında ve 120 dakika bekleme süresinde giderim verimleri karşılaştırıldığında fenton prosesi için KOI ve TOK verimleri \%83.91 ve \%57.52 ve fotofenton prosesi için ise $\% 90.97$ ve $\% 85.89$ olarak bulunmuştur. Sonuçlar karşılaştırıldığında ise fotofenton prosesinin atıksudan aspirin gideriminde daha etkili bir proses olduğu gözlemlenmiştir. Analiz sonuçları bu hali ile bize ön değerlendirme şansı vermektedir. Ancak kesin olarak giderim verimi ile ilgili sonuç elde edebilmek için kromotografik analizler ile çalışmanın desteklenmesi gerekmektedir.

* $\mathrm{Bu}$ çalışma International Conference on Civil and Environmental Engineering (ICOCEECappadocia2017) konferansında sözlü olarak sunulmuştur.

\section{Kaynaklar}

[1] Bouzenno H., Hfaiedh N., Giroux-Metges M., Elfeki A., Talarmin H., "Biological properties of citral and its potential protective effects against cytotoxicity caused by aspirin in the IEC-6 cells" Biomedicine \& Pharmacotheraphy, 87, 653- 660, 2017.

[2] Deminiat B., Razavipanah I., Rounaghi G. H., Arab-Zavar M. H., "A novel electrochemical imprinted sensor for acetylsalicyclic acid based on polyprole, sol-gel and $\mathrm{SiO}_{2} @ \mathrm{Au}$ core-shell nanoparticles" Sensor and Actuaters B, 244, 785-795, 2017.

[3] Kummerer K., "Pharmaceuticals in the environment" Springer, 527s, USA, 2004. 
[4] Heberer T., "Occurance fate and effects of pharmaceutical residues on the aquatic environment: A review of recent research data" Toxicology Letters, 131 (1/2), 5-17, 2002.

[5] Yunlong L., Wenshan G., Huu H. N., Long D. N., Faisal T.H., Jian Z., Shang L, Xiaocheng C. W., "A review on the occurence of micropollutants in the aquatic environment and their fate and removal during wastewater treatment, Science of the Total Environment, 4734-4740, 619-641, 2014.

[6] Liu W., Wang Y., Zhang L., "Hydrothermal synthesis of $\mathrm{FeS}_{2}$ as a high effiency fenton reagent to degrade alachlor via superoxide-mediated $\mathrm{Fe}$ (II)/ Fe(III) cycle, ACS Applied Materials\&Interfaces, 7, 28534-28544, 2015.

[7] Sonmez G., "İleri oksidasyon prosesleri ile bazı ilaç kalıntılarının giderimi” Aksaray Üniversitesi, Fen Bilimleri Enstitüsü, Doktora Tezi, 97s, Aksaray, 2015.

[8] Anipsitakis G. P., Dionysiou D. D., "Transition metal/UV based advanced oxidation technologies for water decontamination, Applied Catalysis B: Environmental, 54(3), 155-163, 2004.

[9] Li W., Nanaboina V., Zhou Q., Korshin G. V., "Effects of fenton treatment on the properties of effluent organic matter and their relationship with degradation of pharmaceuticals and personal care products" Water Research, 46, 403-412, 2012.

[10] Akbal F., Balkaya N., "Toksik organik kirleticilerin gideriminde ileri oksidasyon teknolojileri, Yıldız Teknik Üniversitesi Dergisi, 4, 47-55, 2002.

[11] http://www.enviolet.com/en/uv-oxidation/uvoxidation/photo-fenton-reaction.html [Erişim Tarihi:3.05.17]

[12] https://www.astm.org/Standards/D1252.htm [Erişim Tarihi: 3.05.2017]

[13] Trapido M., Kulik N., Goi A., Veressinina Y., Muntar R., “ Fenton treatment efficacy for the purification of different kinds of wastewater" Water Science and Technology, 60(7), 1795-1801, 2009.

[14] Tekin H., Bilkay O., Ataberk S. S., Balta T. H., Ceribasi I. H., Sanin F. D., Dilek F. B., Yetis U., "Use of fenton oxidation to improve the biodegradability of a pharmaceutical wastewater" Journal of Hazardous Materials B, 136, 258-265, 2006.

[15] Ustun Odabasi S., Maryam B., Buyukgungor H., "Assessment and investigation of paracetamol from wastewater by using oxidation process and TOC" 3rd International on Recycling and Reuse, 28-30 Eylül, Full paper book, 161s, İstanbul, 2016.

[16] Ustun Odabasi S., Buyukgungor H., "Investigation and evaluation of degradability of ibuprofen from wastewater by using fenton process" EJENS- European Journal of Engineering And Natural Sciences, 2(1), 114-119, 2017.

[17] Kang Y. W., Hwang K., "Effect of reaction conditions on the oxidation efficiency in the fenton process” Water Research, 10, 2786-2790, 2000. 